\title{
Probable Role of Bilophila wadsworthia in Appendicle Infection
}

\author{
Mohammad Tabatabaei (PhD) \\ Microbiologist, Department of \\ pathobiology, Faculty of Veterinary \\ Medicine, Shiraz University, Shiraz, \\ Iran \\ Aslam Dehvary (MSc) \\ Department of Pathobiology, Faculty \\ of Veterinary Medicine, Shiraz \\ University, Shiraz, Iran \\ Bita Geramizadeh (PhD) \\ Pathologist, Shiraz Transplant \\ Research Center, Shiraz University of \\ Medical Sciences, Shiraz, Iran \\ Mohammad Hadi Niakan (MD) \\ Surgeon, Trauma Research Center, \\ Shiraz University of Medical Sciences, \\ Shiraz, Iran \\ Corresponding author: Mohammad \\ Tabatabaei \\ Tel: +987136138696 \\ Email: mtabatabaei2003@yahoo.co.uk \\ Address: Trauma Research Center, \\ Shiraz University of Medical Sciences, \\ Shiraz, Iran \\ Received: 02 Jan 2018 \\ Revised: 02 Jan 2019 \\ Accepted: 20 Jan 2019

\section{(c) (i) (8)} \\ This work is licensed under a Creative \\ Commons Attribution 4.0 License.
}

\begin{abstract}
Background and 0bjective: Bilophlia spp. are gram-negative, pleomorphic rod, obligate anaerobe, oxidase-negative, catalase-positive and non-motile bacteria. $B$. wadsworthia is type species of genus Bilophila with the additional characteristic of urea hydrolysis. B. wadsworthia can be found in a variety of anaerobe infections, particularly appendicitis and intra-abdominal infection that are considered as important opportunistic pathogens.
\end{abstract}

Methods: This study was designed to identify Bilophila spp. in clinical specimens by culture and PCR. We examined 91 DNA samples extracted from infected appendix tissues with specific primers.

Results: Data showed that Bilophila spp. DNA existence in 53.85\% $(\mathrm{n}=49)$ provided appendiceal tissue.

Conclusion: The pathological and molecular examination of infected appendiceal tissues revealed that $\boldsymbol{B}$. wadsworthia is able to act as the primary cause of significant lesions in the appendicle tissues.

Key words: Bilophila spp., Appendectomy, Appendicle specimens, PCR, Nucleotide sequencing.

This paper should be cited as: Tabatabaei M, Dehvary A, Geramizadeh B, Niakan MH [Probable Role of Bilophila wadsworthia in Appendicle Infection]. mljgoums. 2020; 14(1): 


\section{INTRODUCTION}

The genus Bilophila belongs to Desulfobibrionacea in Delta subdivision of protobacteria (1). The strictly anaerobic bacterium Bilophila wadsworthia is a gramnegative, bile tolerant, strong catalase positive, non-motile, indole negative, urease positive and non-spore forming rod. The preferred ecological niche of Bilophila spp. is unknown but presumably located in the lower gastrointestinal tract. Bilophila spp. is considered as virulent because it is the third most common anaerobic isolate in the studies of gangrenous and perforated appendicitis; however, it is present in the feces of about $50 \%$ of humans in the mean counts of only $10^{5}$ to $10^{6} / \mathrm{g}$ (with total flora counts of $10^{11} / \mathrm{g}$ ) (2). B. wadsworthia, originally recovered from infections in patients with gangrenous and perforated appendicitis (3), was also isolated from a variety of other clinical specimens, including pleural fluid, joint fluid, blood and pus from a scrotal abscess, mandibular osteomyelitis and axillary hidradenitis suppurativa $(4,5,6)$. B. wadsworthia was named for its apparent requirement for $20 \%$ bile in the growth medium (7). B. wadsworthia is also found in intra-abdominal infections, especially appendicitis and extra-abdominal infections, gastrointestinal tract, oral cavity, vaginal fluids of asymptomatic adults, and even the periodontal pockets of dogs (8). The first report on the isolation of $B$. wadsworthia from non-human sources was in pigs (9). $B$. wadsworthia is considered as an opportunistic pathogen in appendicitis and other intraabdominal infection due its presence in advanced stages of infection $(10,13)$. Therefore, this study was designed to investigate the occurrence and probable role of B. wadsworthia in the appendectomy specimens of patients who had undergone surgery to treat the initial diagnosis of acute appendicitis.

\section{MATERIALS AND METHODS}

A total of 91 appendiceal tissues and contents were obtained aseptically by surgery from patients who had undergone appendectomy to treat an initial diagnosis of acute appendicitis in Namazi hospital (Shiraz, Iran) over a 9month period (October 2015-June 2016). The diagnosis of appendicitis was made by the pathologic examination of the appendiceal tissue. The landmark of pathology or the diagnosis of appendicitis as the gold standard is the presence of inflammatory cells in the wall, lumen and serosa of the appendix. The samples were immediately transferred to microtube containing thioglycollate media; after that, they were transferred beside the ice comperes to the laboratory of the Bacteriology Faculty of Veterinary Medicine, Shiraz University, Shiraz, Iran. To obtain the strains and compare the culture and PCR results, cultures were initially performed as enrichment cultures. All microtubes containing samples were vortexed, placed beside Anaerocult A (Merck, Germany) in an anaerobic jar, and incubated for $72 \mathrm{~h}$ at $37^{\circ} \mathrm{C}$. Initial enriched cultures were transferred to the enrichment culture plates by serially streaking the cultures on Bacteroides Bile Esculin (BBE) agar and blood agar plates; they were then incubated under anoxic conditions at $37^{\circ} \mathrm{C}$. Pseudomonas aeruginosa were used for testing the anaerobic condition.

A $100 \mu 1$ sample of enrichment culture was used for DNA extraction. Total DNA was prepared from enrichment cultures using the Gram negative DNA extraction kit (Cinnagen, Iran). For extractions, the protocol for Gram negative bacteria was followed as described in the kit. The extracted DNA were determined to be of good quality, and DNA concentration was measured using Nanodrop $(10000 \mathrm{~V}$ 3.52). DNA concentrations were adjusted to $15 \mathrm{ng} \mu \mathrm{L}^{-1}$ prior to PCR amplification. Ultimately, the extracted DNA samples were stored at $-20^{\circ} \mathrm{C}$ for further use.

Primers targeting the $16 S r R N A$ gene of $B$. wadsworthia, obtained from previously published work, amplified the $16 \mathrm{~S}$ rDNA gene of the type strain (ATCC 49260, Gen-Bank accession no. L35148) (11).

PCR was carried out in two steps as semi nested reaction. In the first step, the final reaction mixture solution was prepared in 25 $\mu \mathrm{l}$ volume for each reaction which contained

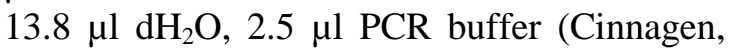
Iran), $1.5 \mu \mathrm{l}$ (1.5 mM) $\mathrm{MgCl}_{2}$ (Cinnagen, Iran), $1.5 \mu \mathrm{l}(200 \mathrm{mM}) \mathrm{dNTPs}$ (Cinnagen, Iran), 1.5 $\mu \mathrm{l}(100 \mathrm{nmol})$ of both BWf (5'GAATATTGCGCAATGGGC3') and BWr (5'TCTCCGGTACTCAAGCGTG3')

oligonucleotide primers, $1 \mathrm{U}$ of Taq DNA polymerase (Cinnagen, Iran), and $3 \mu \mathrm{l}$ template DNA samples. In the second step, semi Nested PCR was done on the PCR 
product of the first reaction. The final reaction mixture solution was the same as in the first step, but its reverse primer was BWn (5'CGTGTGAATAATGCGAGGG3').

Following the initial denaturation (at $94^{\circ} \mathrm{C}$ for $4 \mathrm{~min}$ ), amplification conditions were: denaturation at $94^{\circ} \mathrm{C}$ for $1 \mathrm{~min}$, annealing at $49^{\circ} \mathrm{C}$ for $1 \mathrm{~min}$, and extension at $72^{\circ} \mathrm{C}$ for one minute. This was repeated for 30 cycles in a Block assembly 96G thermocycler with a hot top assembly (Analytic Jena, Germany), with a final extension of $72^{\circ} \mathrm{C}$ for $7 \mathrm{~min}$; the PCR products remained in the thermal cycler at $4^{\circ} \mathrm{C}$ until they were collected. The preparation of the reagents for PCR, addition of the DNA extracts to the mixture, and PCR thermocycling were performed in three separate rooms to prevent crossover contamination by extraneous nucleic acids. A duplex PCR with all three primers and the same amplification conditions was further performed as a complimentary reaction.

The purified DNA of $B$. wadsworthia, kindly donated by Dr. David Schleheck (University of Konstanz, Konstanz, Germany), were used as appropriate positive controls, and sterile nuclease free distilled water was employed as a negative control. Control positive DNA samples were used to test PCR validity, consistently resulting in the expected PCR products of 305 and $207 \mathrm{bp}$, respectively. Electrophoresis was performed to examine the PCR products. PCR amplicons were assessed by loading $8 \mu \mathrm{l}$ of the PCR product plus $2 \mu \mathrm{l}$ of loading buffer into separate wells of a $2 \%$ (w/v) agarose gel (Agarose I; Cinnagen, Iran) containing ethidium bromide $(0.5 \mu \mathrm{g} / \mathrm{ml})$. A molecular weight marker (50 bp; Cinnagen, Iran) was loaded into the first well so as to detect the PCR product size. The gel was immersed in TBE buffer and subjected to a voltage difference of $100 \mathrm{~V}$ which separated the fragments. Visualization was undertaken using an ultraviolet transilluminator (BTS-20, Japan), and the resulting image was captured by a computer software program (AlphaEase; Alpha Innotech). For final confirmation, the partial nucleotide sequencing of nucleotide (nt) 38 to 492 of the 16SrRNA gene was performed by PCR amplification using primers 5'GAATATTGCGCAATGGGC3' and 5'TCTCCGGTACTCAAGCGTG3' and subsequent sequence analysis on an ABIPrism 3100 Genetic Analyzer (Applied Biosystems, Inc.). Sequences were further compared with previously available sequences in NCBI (National Center for Biotechnology Information) using BLAST (Basic Local Alignment Search Tool) (GenBank accession no. U82813.1) (12).

Figure 1- Amplification fragment of $16 \mathrm{~S}$ rDNA gene by BWf and BWr primer (305 bp). Lane 1: 50bp DNA size marker, Lane 2: negative control, Lane 3: positive control, Lanes 4-8: some positive samples

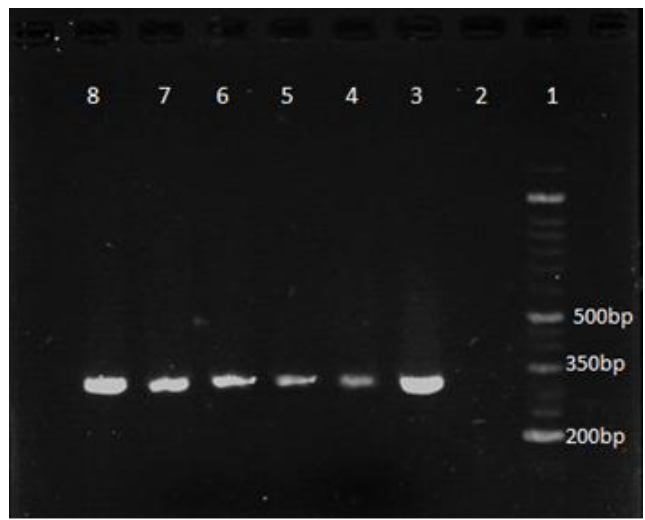

Figure 2- Amplification fragment of 16S rDNA gene by BWr and BWn primer in semi nested PCR (207 bp). Lane 1: 50bp DNA size marker, Lane 2: negative control, Lane 3: positive control, Lanes 4-8: some positive samples

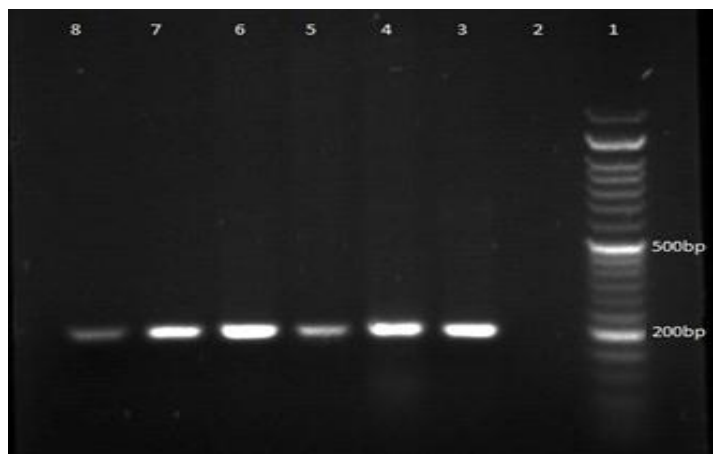


Figure 3- A duplex PCR amplification of 16SrDNA gene by BWf and BWr primers (305 bp) and BWr and BWn primers (207 bp). Lane 1: 50bp DNA size marker, Lane 2: positive control, Lane 3: negative control, Lanes 4-8: some positive samples

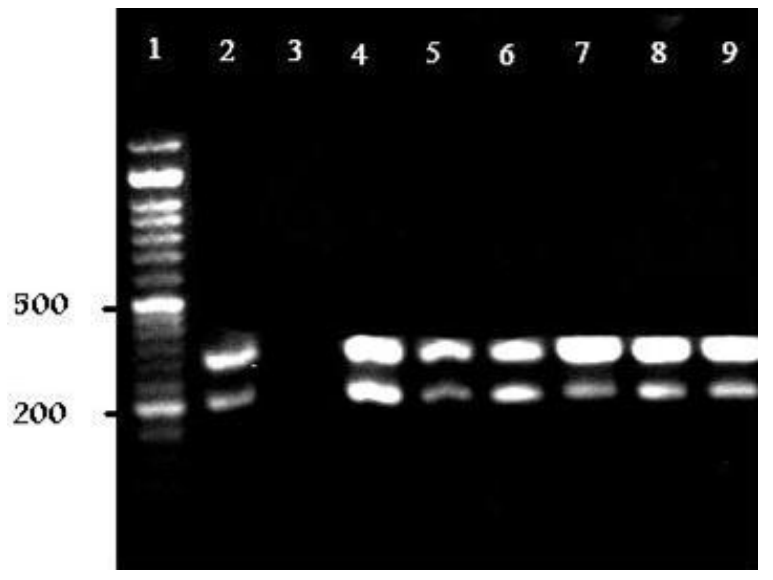

\section{RESULTS}

Attempts were made to isolate $B$. wadworthia from appendicle tissues through culture and PCR methods. According to our findings, no colonies were grown out of the 91 cultures enriched on BBE and blood agar plates. DNA extracted from 91 enrichment cultures were used as the template for the $16 \mathrm{~S}$ rRNA specific primer pairs. We used two primer sets for semi nested PCR which amplified the fragments of $16 \mathrm{~S} r D N A$ gene of B. wadsworthia and yielded 305 and $207 \mathrm{bp}$ PCR fragments (Figure. 1 and 2). The primer set was tested on the B.wadsworthia purified DNA sample donated by Dr. David Schleheck (University of Konstanz, Konstanz, Germany). A duplex PCR with all three primers and same amplification conditions was done as a complimentary reaction (Figure 3 ).

The presence of $B$. wadsworthia DNA in the enrichment cultures was, therefore, indicated by the positive PCR reactions for $16 S$ rDNA gene, and corresponded well with the results obtained by DNA sequencing (see above).

Table 1- The PCR results on the basis of sex

\begin{tabular}{|c|c|c|c|c|}
\hline & & \multicolumn{2}{|c|}{ PCR } & \multirow[t]{2}{*}{ Total } \\
\hline & & Negative & Positive & \\
\hline \multirow[t]{3}{*}{ Sex } & Male & 25 & 29 & 54 \\
\hline & Female & 18 & 19 & 37 \\
\hline & Total & 43 & 48 & 91 \\
\hline
\end{tabular}

Table 2- The PCR results on the basis of pathologic diagnosis

\begin{tabular}{|c|c|c|c|}
\hline Pathologic Diagnosis & \multicolumn{2}{|c|}{ PCR results } & Total \\
\hline & Negative & Positive & \\
\hline No specific pathologic changes & 6 & 2 & 8 \\
\hline $\begin{array}{l}\text { Acute suppurative appendicitis and } \\
\text { periappendicitis }\end{array}$ & $\mathbf{0}$ & 3 & 3 \\
\hline $\begin{array}{l}\text { Early acute } \\
\text { periappendicitis }\end{array}$ & 2 & 2 & 4 \\
\hline $\begin{array}{l}\text { Acute appendicitis } \\
\text { periappendicitis }\end{array}$ & 23 & 28 & 51 \\
\hline Follicular hyperplasia & 7 & 6 & 13 \\
\hline Fibrotic appendix & 2 & $\mathbf{0}$ & 2 \\
\hline Fecalith & $\mathbf{0}$ & 3 & 3 \\
\hline Gangrenous appendicitis & 1 & 4 & 5 \\
\hline Perforated gangrenous appendicitis & 1 & 1 & 2 \\
\hline Total & 42 & 49 & 91 \\
\hline
\end{tabular}

Furthermore, 25 samples of infected appendicles tissue were compared with 25 pathologically normal tissues; 10 out of 25 normal tissues were positive by PCR while from the 25 infected appendicles, 17 were positive by PCR (Table 3). 
Table 3- The Results of PCR on the basis of infected or normal appendicles tissues

\begin{tabular}{|c|c|c|c|c|}
\hline & & \multicolumn{2}{|c|}{ PCR results } & \\
\hline & & Negative & Positive & \\
\hline \multirow[t]{2}{*}{ Infection } & Negative & 15 & 10 & 25 \\
\hline & Positive & 8 & 17 & 25 \\
\hline Total & & 23 & 27 & 50 \\
\hline
\end{tabular}

Figure 4-Alignment results of Bilophila spp. partial 16S rRNA gene with 16S rRNA gene sequence of some Bilophila isolates

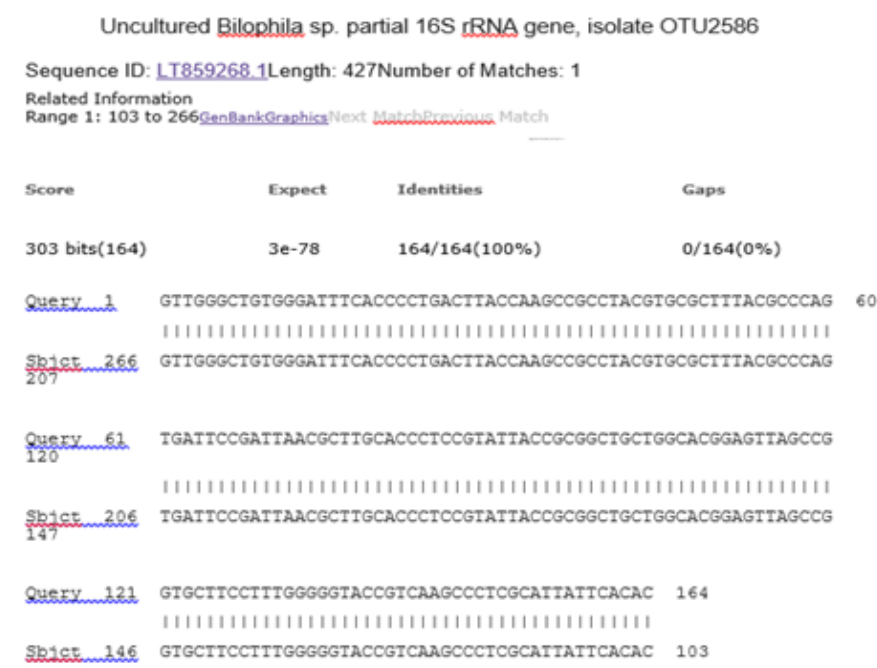

The nucleotide sequences of $16 \mathrm{~S}$ rRNA gene PCR product of some recently identified samples showed $100 \%$ homology with the previously published $B$. wadsworthia sequences in GenBank (accession no. U82813.1) (Figure 4-).

\section{DISCUSSION}

Whereas biochemical methods are still employed to identify the rapidly growing bacterial strains in the clinical microbiology laboratories, molecular methods are becoming more common for the identification of slowly growing strains. These methods are further utilized in identifying the strains in the case of inconclusive phenotypical data. There are currently several molecular methods for identification and differentiation of bacterial species, among which 16S rRNA gene sequencing is regarded as the "gold standard" for bacterial identification.

The preferred ecological niche of Bilophila spp. is unknown, but it is presumably the lower gastrointestinal tract. However, this organism is occasionally found in the oral and vaginal floras. Bilophila spp. is considered to be virulent because it is the third most common anaerobic isolate in studies of gangrenous and perforated appendicitis; however, it is present in the feces of about $50 \%$ of humans in the mean counts of only $10^{5}$ to $10^{6} / \mathrm{g}$ (with total flora counts of $10^{11} / \mathrm{g}$ ) (3). B. wadsworthia also has a clinical importance owing to its presence in a variety of clinical infections such as anaerobic infection, intraabdominal infection, and appendicitis. Investigations have shown that this species exists in advanced stages of infection $(2,5$, 13). Scientists in Helsinki, Finland (13) isolated 28 strains from patients with appendicitis (approximately half of the studied subjects), which is in accordance with the experiments of a group at the Wadsworth Anaerobe Laboratory $(2,13,14-16)$. Based on the results of the first experiment, we were not sure about the exact role of $B$. wadsworthia in appendicitis; therefore, we decided to specify it, for first time, as normal flora or pathogen, exactly in appendisitis. For this reason, 25 normal and 25 infected appendical specimens were compared; the same sex and age were almost kept in view to determine the presence of Bilophila spp. in non-infected tissues specified by the gold standard of pathologic diagnosis. Schumacher et al., evaluated the incidence of $B$. wadsworthia in appendiceal, peritoneal and fecal samples obtained from children. B wadsworthia was. 
recovered from $25 \%$ and $28.5 \%$ of the patients with non-infected and chronically inflamed appendices, respectively, whereas $53.8 \%$ and $64.2 \%$ of the patients with acute and complicated appendicitis showed $B$. wadsworthia growth, respectively (17). In two recent studies focused on the bacteriology of appendicitis, B. wadsworthia was recovered in $46 \%$ of the tissue samples, as well as Bacteroides fragilis, Bacteroides thetaiotaomicron and Peptostreptococcus micros, with a mean recovery rate of more than seven anaerobes in complicated appendicitis cases $(2,13)$. Baron et al. reported that the recovery rate of $B$. wadsworthia increased according to the grade of appendicitis (2).

Feng et al. observed that a human stoolderived $B$. wadsworthia strain inoculated in specific-pathogen-free mice caused systemic inflammation, adding new evidence to the pathogenicity of this bacterium and implying its potential role in chronic inflammation related metabolic diseases such as diabetes (18).

In the present research, we evaluated 91 samples of inflamed appendix which were appediceal tissues with acute inflammatory cells in the wall within their lumens. The presence of $B$. wadsworthia was investigated by culture and PCR, which is the highest number of appendical tissue evaluated to find the foot print of $B$. wadsworthia. Data showed

\section{REFERENCES}

1. Laue H, Friedrich M, Ruff J, Cook AM. Dissimilatory sulfite reductase (desulfoviridin) of the taurinedegrading, non-sulfate-reducing bacterium Bilophilawadsworthia RZATAU contains a fused DsrBDsrD subunit. J Bacteriol. 2001; 183(5): 1727-1733. DOI: 10.1128/JB.183.5.1727-1733.2001.

2. Baron EJ, Bennion R, Thompson J, Strong C, Summanen P, McTeague M, Finegold SM. A microbiological comparison between acute and complicated appendicitis. Clin Infect Dis. 1992; 14(1): 227-231. doi.org/10.1093/clinids/14.1.227.

3. Baron EJ, Summanen P, Downes J, Roberts MC, Wexler H, Finegold SM. Bilophila wadsworthia, gen. nov. and sp. nov., a unique gram-negative anaerobic rod recovered from appendicitis specimens and human faeces. J Gen Microbiol. 1989; 135(12): 3405-11.

4. Baron EJ, Curren M, Henderson G, Jousimies-Somer $\mathrm{H}$, Lee K, Lechowitz K, Strong CA, et al. Bilophila wadsworthia isolates from clinical specimens. J Clin Microbiol. 1992; 30:1882-1884. the significant connectedness between infection and presence of Bilophila spp. in appendix $(\mathrm{P}=0.047)$. Therefore, Bilophila spp. can surely be introduced as an opportunistic pathogen in appendicitis.

\section{CONCLUSION}

Clear differences were observed between normal and infected appendicle samples regarding the presence of Bilophila DNA. Therefore, based on the pathological and molecular examination of positive appendicle tissues, $B$. wadsworthia is capable of acting as an important cause of significant lesions in the appendicle tissues. According to the literature, the frequent occurrence of $B$. wadsworthia in inflamed appendices, its association with other known anaerobic pathogens, and its recovery from infectious processes such as appendicitis are suggestive of pathogenic properties in this species.

\section{ACKNOWLEDGEMENTS}

The authors wish to thank the staff members of the Department of Pathobiology and all those who collaborated with the authors, particularly the laboratories of microbiology and biotechnology, Faculty of Veterinary Medicine, Shiraz University, Iran. The research was funded by Shiraz University (Grant no. S9331242).

\section{CONFLICTS OF INTEREST}

None to declare.

5. Summanen PH, Jousimies-Somer H, Manley S, Goldstein EJC, Finegold SM. Bilophila wadsworthia isolates from clinical specimens. Clin Infect Dis. 1995; 20 (Suppl 2): S210-1

6. Finegold S, Summanen P, Gerardo SH, Baron E. Clinical importance of Bilophila wadsworthia. Eur J Clin Microbiol Infect Dis. 1992; 11(11): 1058-63.

7. Laue H, Smits TH, Schumacher UK, Claros MC, Hartemink R, Cook AM. Identification of Bilophila wadsworthia by specific PCR which targets the taurine: pyruvate aminotransferase gene. FEMS Microbiol Lett. 2006; 261(1): 74-79.

8. Urbán E, Hortobágyi A, Szentpáli K, Nagy E. Two intriguing Bilophila wadsworthia cases from Hungary. $\mathrm{J}$ Med Microbiol. 2004; 53(11): 1167-1169.

9. McOrist AL, Warhurst M, McOrist S, Bird AR. Colonic infection by Bilophila wadsworthia in pigs. $\mathrm{J}$ Clin Microbiol. 2001; 39(4): 1577-9. 
10. Da Silva SM, Venceslau SS, Fernandes CL, Valente FM, Pereira IA. Hydrogen as an energy source for the human pathogen Bilophila wadsworthia. Antonie Van Leeuwenhoek. 2008; 93(4): 381-390.

11. Sapico FL, Reeves D, Wexler HM, Duncan J, Wilson KH. and Finegold SM. Preliminary study using speciesspecific oligonucleotide probe for rRNA of Bilophila wadsworthia. J Clin Microbiol. 1994; 32 (10): 25102513.

12. Laue H, Denger K. and Cook AM. Taurine reduction in anaerobic respiration of Bilophila wadsworthia. Appl Environm Microbiol. 1997; 63(5): 2016-2021.

13. Bennion RS, Baron EJ, Thompson JE Jr, Downes J, Summanen P, Talan DA, Finegold SM. The bacteriology of gangrenous and perforated appendicitis-revisited. Annual Surgery. 1990; 211(2): 165-171.

14. Bennion, RS, Thompson JE, Baron EJ, Finegold SM. Gangrenous and perforated appendicitis with peritonitis: treatment and bacteriology. Clin Ther. 1990; 12 (Suppl C): $31-44$.
15. Gerardo SH, Marina M, Citron DM, Claros MC, Hudspeth MK, Goldstein EJC. Bilophila wadsworthia clinical isolates compared by polymerase chain reaction fingerprinting. Clin Infect Dis. 1997; 25(Suppl 2): S2914.

16. Finegold SM, Bennion RS, Thompson JE, Wexler HM, Baron EJ. Gangrenous and/or perforated appendix: clinical outcome and in vitro susceptibility testing. Hospital Practice. 1990; 25(S4): 3-12.

17. Schumacher UK, Eiring P, Häcker FM. Incidence of Bilophila wadsworthia in appendiceal, peritoneal and fecal samples from children. Clin Microbiol Infect. 1997; 3(1): 134-136.

18. Feng Z, Long W,Hao B, Ding D, MaX,Zhao L, Pang $\mathrm{X}$. A human stool-derived Bilophilawadsworthia strain caused systemic inflammation in specific-pathogen-free mice. Gut Pathology. 2017; 9: 59. DOI 10.1186/s13099017-0208-7. 